\title{
Enhancing the estimation of throughfall amounts in primeval forests along an elevation gradient on Mountain Gongga, Southwest China
}

\author{
Ruxin Yang ${ }^{1}, \mathrm{Li}_{\mathrm{Guo}}{ }^{2}$, Junfang Cui ${ }^{1}$, Genxu Wang ${ }^{2}$, Fei Wang ${ }^{1}$, and Xiang-Yu Tang ${ }^{1}$ \\ ${ }^{1}$ Institute of Mountain Hazards and Environment Chinese Academy of Sciences \\ ${ }^{2}$ Sichuan University
}

October 25, 2021

\begin{abstract}
Differences in rainfall partition into throughfall among different primeval forests distributed along an altitude gradient are inadequately investigated and understood. Through continuous and automatic monitoring of natural rainfall and throughfall along an elevation gradient on Mountain Gongga, we examined the response of throughfall to various rainfall patterns in the broadleaved forest $(\mathrm{BF})$, broadleaved-coniferous mixed forest (MF) and coniferous forest (CF) across individual rain events from May to October in 2019. A series of linear models that estimate throughfall amount were obtained and compared. Results showed that throughfall was jointly controlled by rainfall characteristics (including amount, duration, average and peak intensity) and leaf area index (LAI). Rainfall amount was the primary control for throughfall amount. The models with all rainfall parameters and LAI as variables did not markedly outperform (R2 enhancement by 0-0.02) than the simple linear models with rainfall amount as the only variable; therefore, the latter are recommended due to simplicity and easiness of use. Although the correlation of throughfall with LAI was less prominent compared to rainfall parameters, LAI showed a significant positive linear correlation $(\mathrm{p}<0.05)$ with the estimated rainfall amount threshold (the rainfall required to saturate the canopy) by the single-variable linear models at the monthly scale. Over the study period, penetration proportions of rainfall in BF, MF and $\mathrm{CF}$ were $83 \%, 75 \%$ and $80 \%$, respectively. The rainfall amount threshold in CF (0.70 mm) was less than those in BF $(0.80$ $\mathrm{mm})$ and MF (0.92 mm). Rain events of higher intensity exhibited a higher mean penetration proportion than lower intensity rain events. The use of single-variable linear models developed here, despite some overestimations of throughfall amount, could lead to an overall satisfactory estimation of rainfall redistribution in mountainous areas.
\end{abstract}

\section{Hosted file}

Enhancing the estimation of throughfall amounts in primeval forests along an elevation gradient on Moun available at https://authorea.com/users/442779/articles/542960-enhancing-the-estimation-ofthroughfall-amounts-in-primeval-forests-along-an-elevation-gradient-on-mountain-gonggasouthwest-china

\section{Hosted file}

Tables.docx available at https://authorea.com/users/442779/articles/542960-enhancing-theestimation-of-throughfall-amounts-in-primeval-forests-along-an-elevation-gradient-onmountain-gongga-southwest-china 

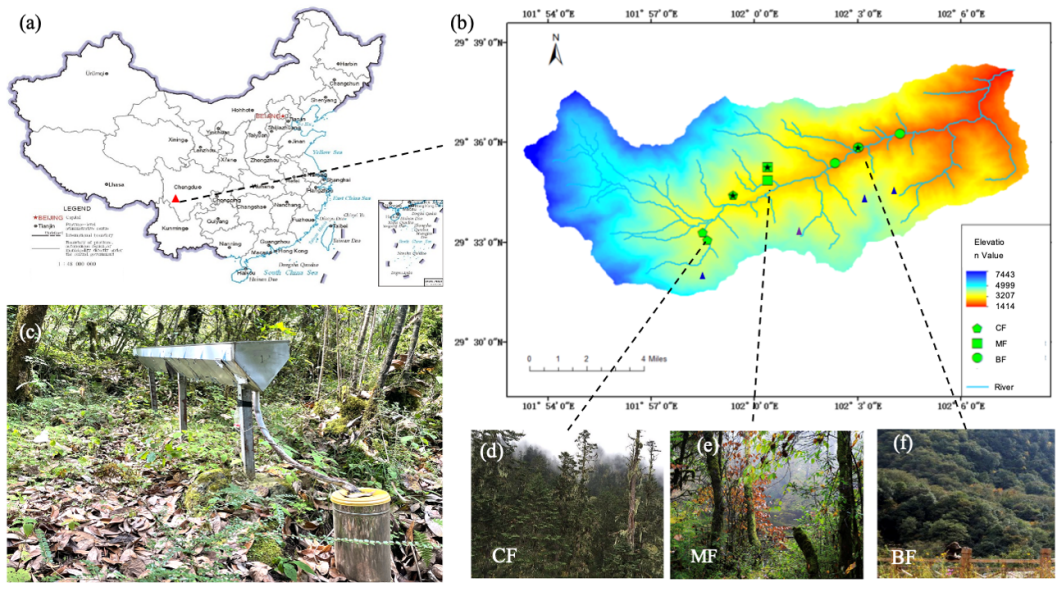

Fig. 1 (a) The location of study site. (b) An overview of the Hailuogou catchment showing the elevation gradient and the locations of the monitoring sites of broadleaved forest (BF), broadleavedconiferous mixed forest (MF) and coniferous forest. (c) The throughfall collector is composed of a $\mathrm{V}$ shaped inclined metal trench connected to a tipping bucket rain gauge. (d), (e) and (f) show the stands in the three vegetation zones.
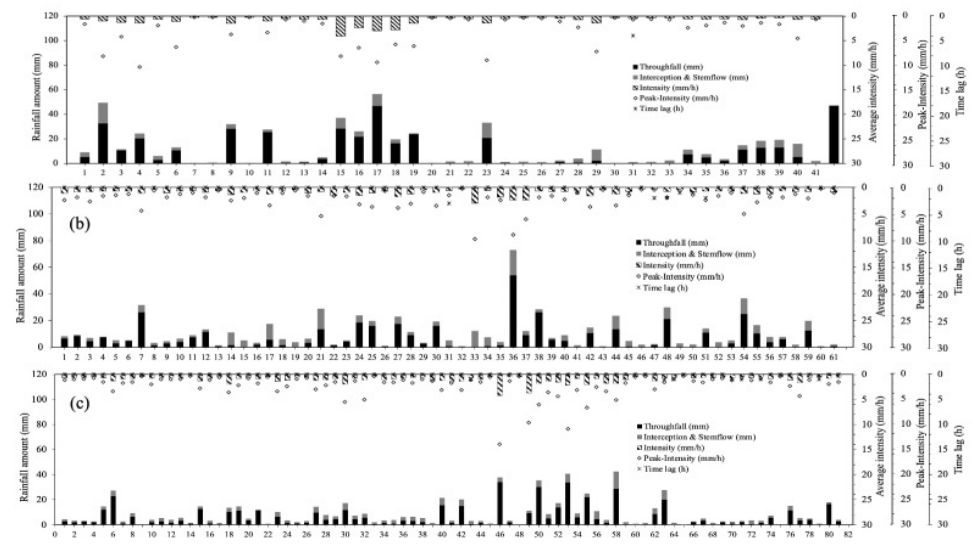

Fig. 2 The rainfall amount $\left(P_{G}\right)$, average intensity $(I n)$, peak intensity $\left(I n_{\text {peak }}\right)$, throughfall amount $(T f)$ and time lag of each event in CF (a), MF (b) and BF (c). 

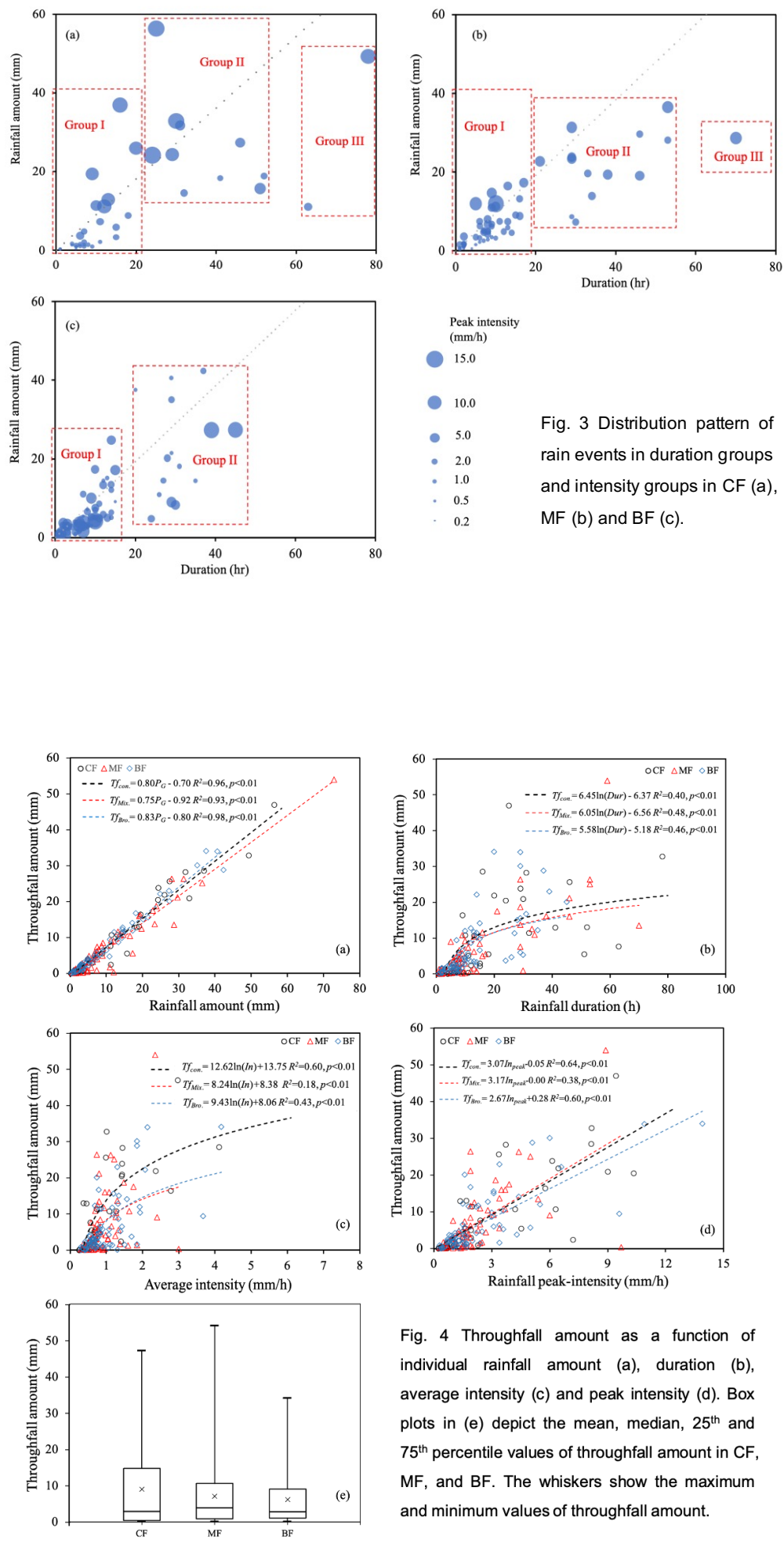

Fig. 4 Throughfall amount as a function of individual rainfall amount (a), duration (b), average intensity (c) and peak intensity (d). Box plots in (e) depict the mean, median, $25^{\text {th }}$ and $75^{\text {th }}$ percentile values of throughfall amount in $\mathrm{CF}$, $\mathrm{MF}$, and BF. The whiskers show the maximum and minimum values of throughfall amount. 

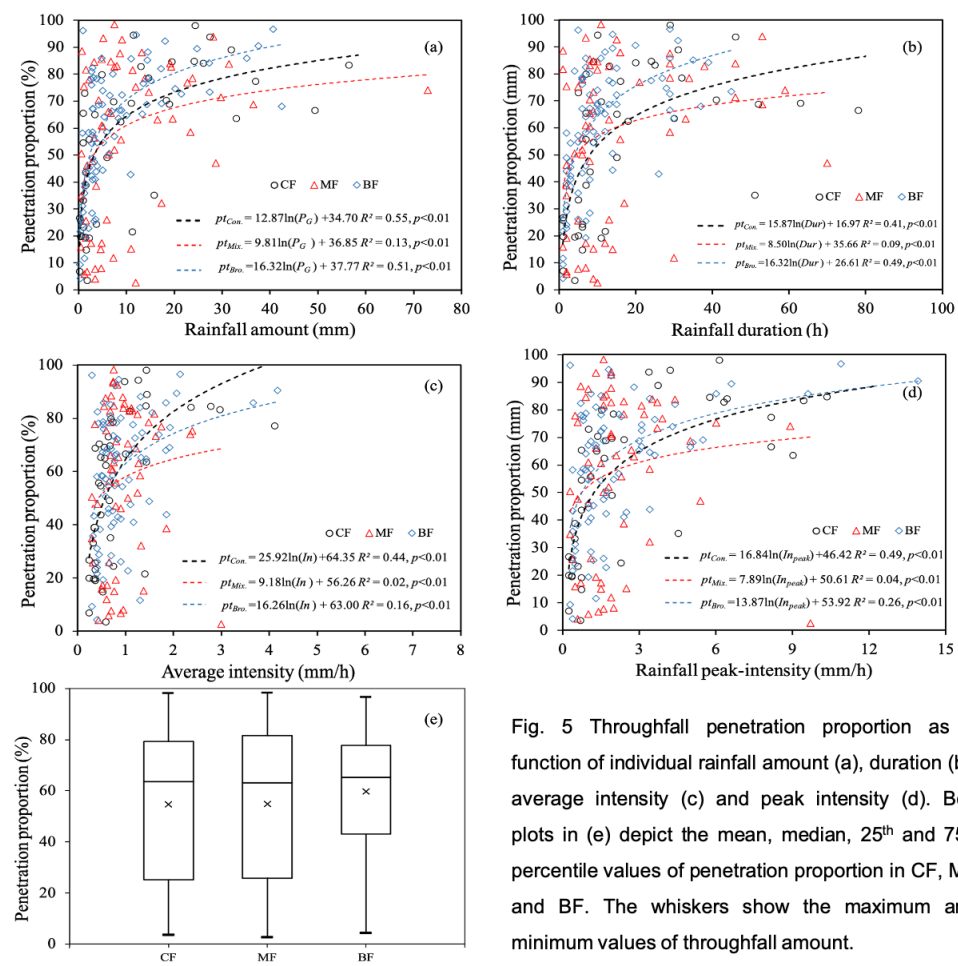

Fig. 5 Throughfall penetration proportion as a function of individual rainfall amount (a), duration (b), average intensity (c) and peak intensity (d). Box plots in (e) depict the mean, median, $25^{\text {th }}$ and $75^{\text {th }}$ percentile values of penetration proportion in $\mathrm{CF}, \mathrm{MF}$, and BF. The whiskers show the maximum and minimum values of throughfall amount.
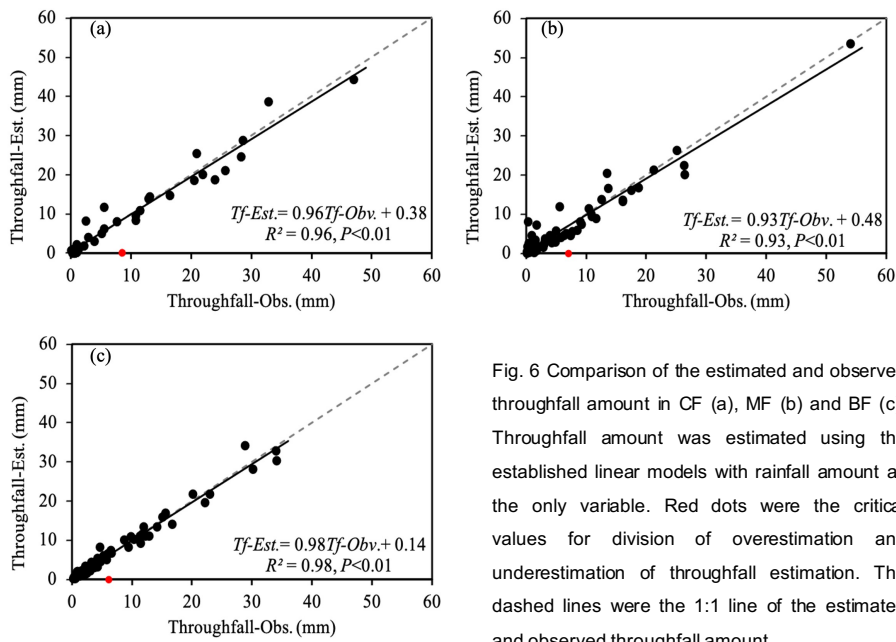

Fig. 6 Comparison of the estimated and observed throughfall amount in CF (a), MF (b) and BF (c). Throughfall amount was estimated using the established linear models with rainfall amount as the only variable. Red dots were the critical values for division of overestimation and underestimation of throughfall estimation. The dashed lines were the 1:1 line of the estimated and observed throughfall amount. 

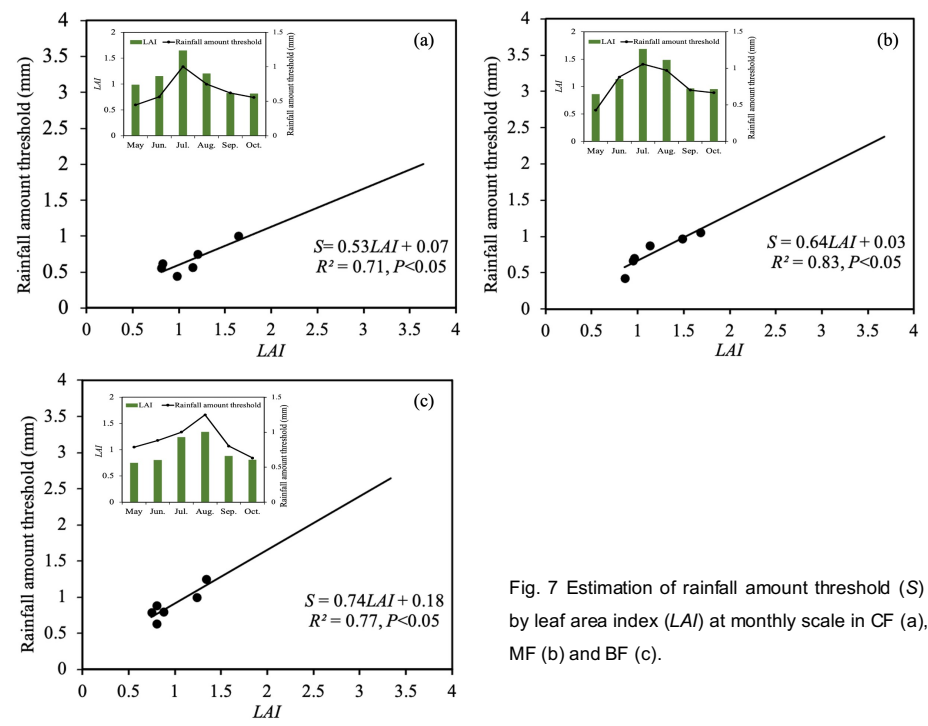

Fig. 7 Estimation of rainfall amount threshold $(S)$ by leaf area index (LAI) at monthly scale in CF (a), $M F(b)$ and $B F(c)$. 